\title{
Newly Synthesized 'Hidabeni' Chalcone Derivatives Potently Suppress LPS-Induced NO Production via Inhibition of STAT1, but Not NF- $\kappa$ B, JNK, and p38, Pathways in Microglia
}

\author{
Hirokazu Hara, ${ }^{*, a}$ Ryoko Ikeda, ${ }^{a}$ Masayuki Ninomiya,${ }^{b}$ Tetsuro Kamiya, ${ }^{a}$ \\ Mamoru Koketsu, ${ }^{b}$ and Tetsuo Adachi ${ }^{a}$ \\ a Laboratory of Clinical Pharmaceutics, Gifu Pharmaceutical University; 1-25-4 Daigaku-nishi, Gifu 501-1196, \\ Japan: and ${ }^{b}$ Department of Chemistry and Biomolecular Science, Faculty of Engineering, Gifu University; 1-1 \\ Yanagido, Gifu 501-1193, Japan. \\ Received February 4, 2014; accepted March 9, 2014
}

\begin{abstract}
Chalcones are open-chain flavonoids that are biosynthesized in various plants. Some of them possess anti-inflammatory activity. We previously found that chalcone glycosides from Brassica rapa L. 'hidabeni' suppress lipopolysaccharide (LPS)-induced nitric oxide (NO) production in rat microglia highly aggressively proliferating immortalized (HAPI) cells. In this study, to explore chalcone derivatives with potent NO inhibitory activity, we synthesized ten compounds based on 'hidabeni' chalcone and examined their effects on LPS-triggered inducible NO synthase (iNOS) expression and NO production. Compounds C4 and C10 potently inhibited NO production ( $\mathrm{IC}_{50}: 4.19,2.88 \mu \mathrm{M}$, respectively). $\mathrm{C} 4$ and $\mathrm{C10}$ suppressed LPS-induced iNOS expression via the inhibition of the signal transduction and activator of transcription 1 (STAT1), but not nuclear factor-kappa B (NF- $\mathrm{B}$ ), c-Jun $\mathrm{N}$ terminal kinase (JNK), and p38, pathways. C10, but not C4, inhibited activation of the MEK/extracellular signal-regulated kinase (ERK) pathway. C4 and C10 also suppressed LPS-induced expression of interferon regulatory factor 1 (IRF-1), which is an important transcription factor involved in iNOS expression. Our findings indicate that these chalcone derivatives are candidate compounds for preventing microglia-mediated neuroinflammation.
\end{abstract}

Key words microglia; nitric oxide (NO); inducible NO synthase; lipopolysaccharide; interferon $\beta$; signal transduction and activator of transcription 1 (STAT1)

There is growing evidence that inflammation is involved in the pathogenesis of neurodegeneration in many central nervous system (CNS) disorders, such as cerebral ischemia and Alzheimer's disease. ${ }^{1-3)}$ Microglia, resident immune cells in the CNS, are activated in response to neuronal injury. Activated microglia produce inflammatory mediators including nitric oxide (NO), superoxide, and proinflammatory cytokines, leading to a robust neuroinflammatory response. ${ }^{4,5)} \mathrm{NO}$ produced by inducible NO synthase (iNOS) rapidly reacts with superoxide to form a highly toxic product, peroxynitrite. This product has been shown to exaggerate neuropathological injury. ${ }^{6)}$ Therefore, suppression of iNOS expression is thought to ameliorate microglia-mediated neurodegeneration.

The induction of iNOS has been reported to be mediated via activation of toll-like receptor 4 (TLR4) in microglia/macrophages. ${ }^{7)}$ Lipopolysaccharide (LPS), an exogenous TLR4 ligand, stimulates TLR4 and provokes several signaling pathways including nuclear factor- $\kappa \mathrm{B}(\mathrm{NF}-\kappa \mathrm{B})$ and the mitogenactivated protein kinase (MAPK) family (c-Jun $\mathrm{N}$ terminal kinase (JNK), p38, and extracellular signal-regulated kinase $(\mathrm{ERK}))^{\left.8{ }^{89}\right)}$ In addition, activation of the interferon- $\beta$ (IFN- $\beta$ ) autocrine loop caused by LPS also plays a key role in LPSinduced iNOS expression. ${ }^{10)}$ Previous reports have demonstrated that TLR4 participates in the exacerbation of ischemic brain injury. ${ }^{7,11}$ It has been demonstrated that damaged or dying cells after cerebral ischemia release damage-associated molecular pattern molecules such as high mobility group box 1 , heat shock proteins, and peroxiredoxin, which are known as endogenous TLR4 ligands, and promote neuroinflammation. ${ }^{2,12)}$

The authors declare no conflict of interest
Chalcones are open-chain flavonoids that are biosynthesized in various plants. Many studies have demonstrated that chalcone derivatives have a variety of biological functions including anti-inflammatory, anti-allergic, and anti-oxidant activities. ${ }^{13-15)}$ Some of them have been reported to inhibit the expression of iNOS and proinflammatory cytokines caused by LPS. Previously, we isolated chalcone glycosides from Brassica rapa L. 'hidabeni,' a popular Japanese turnip, which is mainly cultivated and consumed as a traditional vegetable in Gifu. ${ }^{16)}$ The 'hidabeni' chalcones are 4'-glycosidized-3'oxychalcones, but their structures have rarely been reported. We found that an isolated 'hidabeni' chalcone glycoside has inhibitory effects on LPS-induced NO production in rat microglia highly aggressively proliferating immortalized (HAPI) cells. $^{17)}$

In this study, to explore compounds with more potent inhibitory activity toward LPS-induced iNOS expression and NO production, we newly synthesized ten 'hidabeni' chalcone derivatives and performed a structure activity relationship analysis. Moreover, we also addressed the mechanism by which these compounds inhibit LPS-induced iNOS expression.

\section{MATERIALS AND METHODS}

Chemistry Chalcones C1-C10 were synthesized through the boron trifluoride-etherate $\left(\mathrm{BF}_{3} \cdot \mathrm{Et}_{2} \mathrm{O}\right)$-mediated ClaisenSchmidt reaction of acetophenones and acetylated benzaldehydes, as previously described. ${ }^{17)} \mathrm{BF}_{3} \cdot \mathrm{Et}_{2} \mathrm{O}(6.0 \mathrm{mmol})$ was added to a stirred solution of acetophenones $(1.2 \mathrm{mmol})$ and benzaldehydes $(2.4 \mathrm{mmol})$ in 1,4-dioxane $(10 \mathrm{~mL})$ at room temperature. After stirring for $19 \mathrm{~h}$, the resultant solution was partitioned with EtOAc, washed with $10 \% \mathrm{HCl}$ aq., dis- 


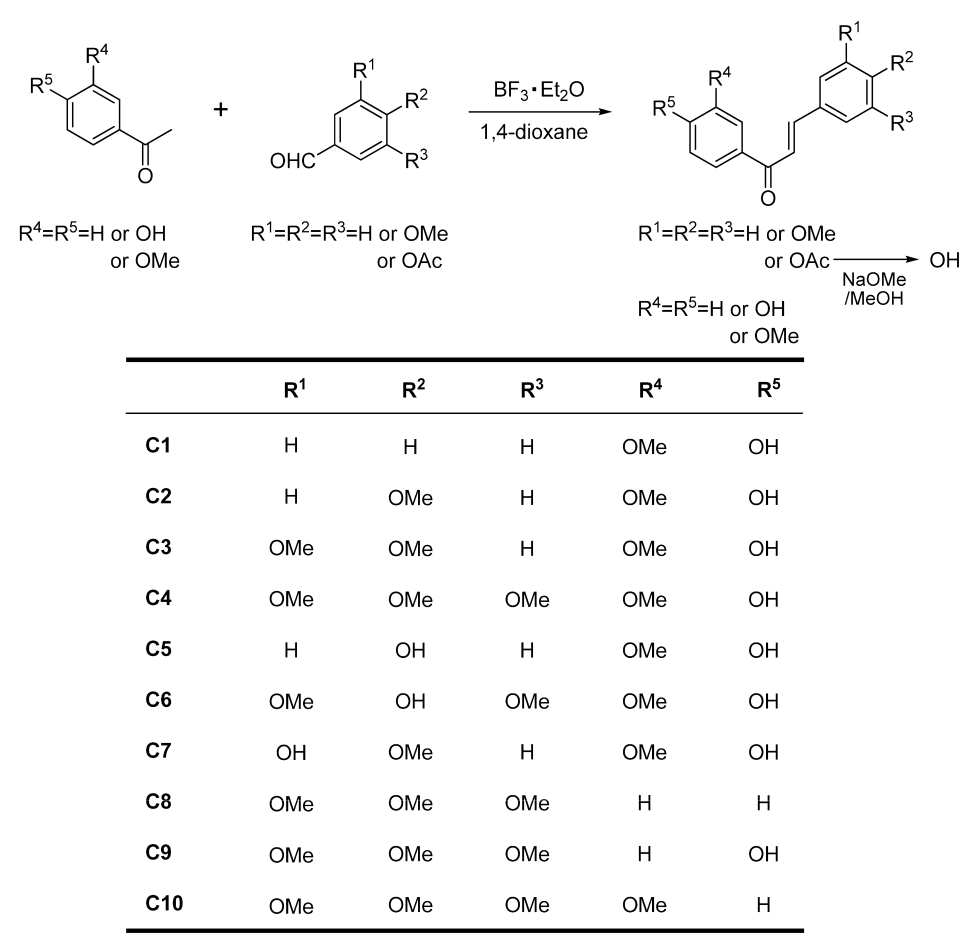

Fig. 1. Synthesis and Chemical Structures of 'Hidabeni' Chalcone Derivatives

tilled water, and brine, dried over anhydrous $\mathrm{Na}_{2} \mathrm{SO}_{4}$, and concentrated in vacuo. The residue was purified by silica gel column chromatography (CC) eluted with $n$-hexane/ $\mathrm{CHCl}_{3}$ $(2 / 1)$ to yield chalcones. Acetylated chalcones were stirred in $10 \mathrm{mg} / \mathrm{mL}$ sodium methoxide/methanol solution $(10 \mathrm{~mL})$ for $10 \mathrm{~min}$. The reaction mixture was neutralized using a Dowex Marathon $\mathrm{C}\left(\mathrm{H}^{+}\right.$form), filtrated, and concentrated in vacuo. The residue was purified by silica gel $\mathrm{CC}$ eluted with $\mathrm{CHCl}_{3} /$ $\mathrm{MeOH}(10 / 1)$ to yield deprotected chalcones C5-C7. Their chemical structures are depicted in Fig. 1.

Materials LPS was purchased from Sigma (St. Louis, MO, U.S.A.). Anti-signal transduction and activator of transcription 1 (STAT1), anti-phospho-JNK (Thr183/Thr185), antiJNK, anti-phospho ERK, anti-ERK, anti-phospho p38, and anti-p38 antibodies were purchased from Cell Signaling Technology (Danvers, MA, U.S.A.). Anti-phospho-STAT1 (Thr701) antibody was purchased from Signalway Antibody (Pearland, TX, U.S.A.). Anti-NF- $\kappa$ B p65 antibody was purchased from Santa Cruz Biotechnology (Santa Cruz, CA, U.S.A.). Antiactin antibody was purchased from Millipore (Billerica, MA, U.S.A.).

Cell Culture and Treatment Rat immortalized microglia HAPI cells were cultured in Dulbecco's modified Eagle's medium (DMEM) containing 10\% heat-inactivated fetal calf serum (FCS), $4 \mathrm{~mm}$ glutamine, 100 units $/ \mathrm{mL}$ penicillin $\mathrm{G}$, and $0.1 \mathrm{mg} / \mathrm{mL}$ streptomycin in a humidified $5 \% \mathrm{CO}_{2} / 95 \%$ air incubator at $37^{\circ} \mathrm{C}$. HAPI cells were seeded in a 6 -cm-diameter dish at densities of $8.0 \times 10^{5}$ cells/dish in DMEM containing $1 \%$ heat-inactivated FCS. The next day, cells were treated with LPS at a concentration of $100 \mathrm{ng} / \mathrm{mL}$ for the time indicated in the Figure legends. Compounds were added to the cultures 30 min prior to treatment with LPS.

Reverse Transcription Polymerase Chain Reaction (RTPCR) Total RNA was extracted from the treated cells with TRIzol reagent (Invitrogen, Carlsbad, CA, U.S.A.). First-strand
cDNA was synthesized from $4 \mu \mathrm{g}$ of total RNA. Aliquots of transcription reaction mixture $(1 \mu \mathrm{L})$ were amplified with primers specific for iNOS (forward primer, 5'-TTGCTTCTG TGC TAA TGC GG-3'; reverse primer, 5'-CAGAAC TGA GGG TACATGCT-3'), IFN- $\beta$ (forward primer, 5'-ATCGACTAC AAGCAGCTCCA-3'; reverse primer, 5'-ACCTTTGTACCC TCCAGTAA-3'), interferon regulatory factor 1 (IRF-1; forward primer, 5'-CAACAA GGA TGC CTG TCT GT-3'; reverse primer, 5'-GCT GTG TAA CTG CTG TGG TC-3'), tumor necrosis factor- $\alpha$ (TNF- $\alpha$; forward primer, 5'-AAA GCA TGA TCC GAGATG TG-3'; reverse primer, 5'-ATC TGC TGG TACCAC CAGTT-3'), interleukin- $\beta$ (IL- $1 \beta$; forward primer, 5'-AGT GTC TGA AGC AGC TAT GG-3'; reverse primer, 5'-TCA TCA TCCCACGAGTCACA-3'), and glyceraldehyde-3-phosphate dehydrogenase (GAPDH: forward primer, 5'-ACCACAGTC CAT GCC ATC AC-3'; reverse primer, 5'-TCC ACC ACC CTG TTGCTGTA-3'). For amplification of iNOS and TNF- $\alpha$, PCR was carried out using EX Taq polymerase (TaKaRa Bio, Otsu, Japan) as follows: $2 \mathrm{~min}$ at $94^{\circ} \mathrm{C}$, one cycle; $40 \mathrm{~s}$ at $94^{\circ} \mathrm{C}, 40 \mathrm{~s}$ at $58^{\circ} \mathrm{C}, 1 \mathrm{~min}$ at $72^{\circ} \mathrm{C}, 27$ and 32 cycles, respectively. For amplification of IFN- $\beta$, PCR was carried out using Taq DNA polymerase (Invitrogen, Carlsbad, CA, U.S.A.) as follows: $2 \mathrm{~min}$ at $94^{\circ} \mathrm{C}$, one cycle; $40 \mathrm{~s}$ at $94^{\circ} \mathrm{C}, 40 \mathrm{~s}$ at $54^{\circ} \mathrm{C}, 1 \mathrm{~min}$ at $72^{\circ} \mathrm{C}, 35$ cycles. For amplification of IRF-1, IL- $1 \beta$, and GAPDH, PCR was carried out using Taq DNA polymerase as follows: $2 \mathrm{~min}$ at $94^{\circ} \mathrm{C}$, one cycle; $40 \mathrm{~s}$ at $94^{\circ} \mathrm{C}, 40 \mathrm{~s}$ at $58^{\circ} \mathrm{C}$, $1 \mathrm{~min}$ at $72^{\circ} \mathrm{C}, 25,30$, and 18 cycles, respectively. Aliquots of the PCR mixtures were separated on $2 \%$ agarose gel and stained with ethidium bromide. Densitometric analyses were performed using the Multi Gauge software (FUJIFILM, Tokyo, Japan). The mRNA levels were normalized relative to the GAPDH mRNA level in each sample.

Measurement of Nitrite Production HAPI cells were seeded in a 24-well plate at a density of $1.0 \times 10^{5}$ cells in DMEM containing $1 \%$ FCS. The next day, the cells were 
treated with $100 \mathrm{ng} / \mathrm{mL}$ LPS in the presence or absence of compounds for $24 \mathrm{~h}$. The nitrite concentrations in the medium were measured by the modified Griess method. Briefly, the medium $(50 \mu \mathrm{L})$ was mixed with $50 \mu \mathrm{L}$ of $1 \%$ sulfanilamide in $5 \%$ phosphoric acid. Five minutes later, it was mixed with $50 \mu \mathrm{L}$ of $0.1 \% \quad N$-1-napthylethylenediamine dihydrochloride in water, followed by incubation for $5 \mathrm{~min}$. The absorbance was measured at $570 \mathrm{~nm}$. A standard curve was prepared with solutions of sodium nitrite.

Preparation of Whole-Cell Lysates and Nuclear Extracts After the treatment, cells were washed twice with ice-cold PBS. For the preparation of whole-cell extracts, the cells were collected using $150 \mu \mathrm{L}$ of lysis buffer (20 mm Tris- $\mathrm{HCl}$, pH 7.4, containing $1 \mathrm{~mm}$ ethylenediaminetetraacetic acid (EDTA), $1 \mathrm{~mm}$ ethylene glycol bis(2-aminoethyl ether)- $N, N, N^{\prime}, N^{\prime}$-tetraacetic acid (EGTA), 1\% Triton X-100, $10 \mathrm{~mm} \mathrm{NaF,} 1 \mathrm{~mm} \mathrm{Na}_{3} \mathrm{VO}_{4}$,
$20 \mathrm{~mm} \beta$-glycerophosphate, $5 \mu \mathrm{g} / \mathrm{mL}$ leupeptin, $1 \mathrm{~mm}$ phenylmethylsulfonyl fluoride (PMSF), and $1 \mathrm{~mm}$ dithiothreitol (DTT)), and were lysed on ice for $30 \mathrm{~min}$. The lysates were centrifuged at $14000 \mathrm{rpm}$ for $10 \mathrm{~min}$ at $4^{\circ} \mathrm{C}$ to remove cellular debris. For preparation of nuclear extracts, the cells were collected using buffer A (20 mM $N$-(2-hydroxyethyl)perazine$N^{\prime}$-2-ethanesulfonic acid (HEPES)-NaOH, pH 7.8, containing $15 \mathrm{~mm} \mathrm{KCl}, 2 \mathrm{~mm} \mathrm{MgCl}_{2}, 5 \mu \mathrm{g} / \mathrm{mL}$ leupeptin, $0.5 \mathrm{~mm}$ PMSF, and $2 \mathrm{~mm}$ DTT) and centrifuged. The cells were lysed in buffer B (buffer A containing 0.2\% Nonidet P-40) for $5 \mathrm{~min}$ on ice and centrifuged. Finally, the pellets were suspended in buffer $\mathrm{C}(20 \mathrm{~mm}$ HEPES-NaOH, pH 7.8, containing $0.4 \mathrm{M}$ $\mathrm{NaCl}, 10 \%$ glycerol, $5 \mu \mathrm{g} / \mathrm{mL}$ leupeptin, $0.5 \mathrm{~mm} \mathrm{PMSF}$, and $2 \mathrm{~mm}$ DTT) and stood on ice for $30 \mathrm{~min}$. The nuclear extracts were centrifuged at $14000 \mathrm{rpm}$ for $10 \mathrm{~min}$ at $4^{\circ} \mathrm{C}$ to remove cellular debris. The protein content of the supernatants was

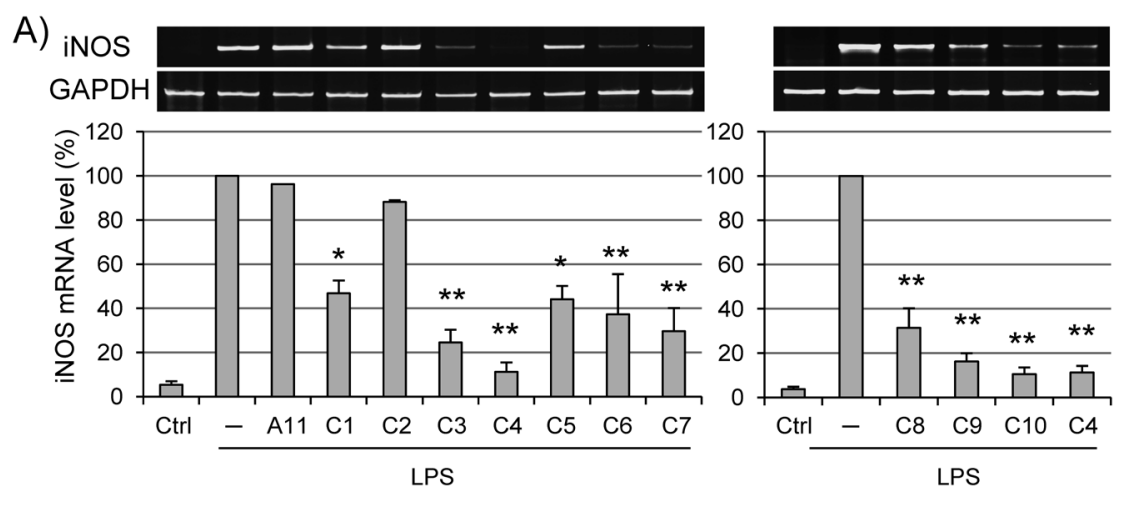

B)

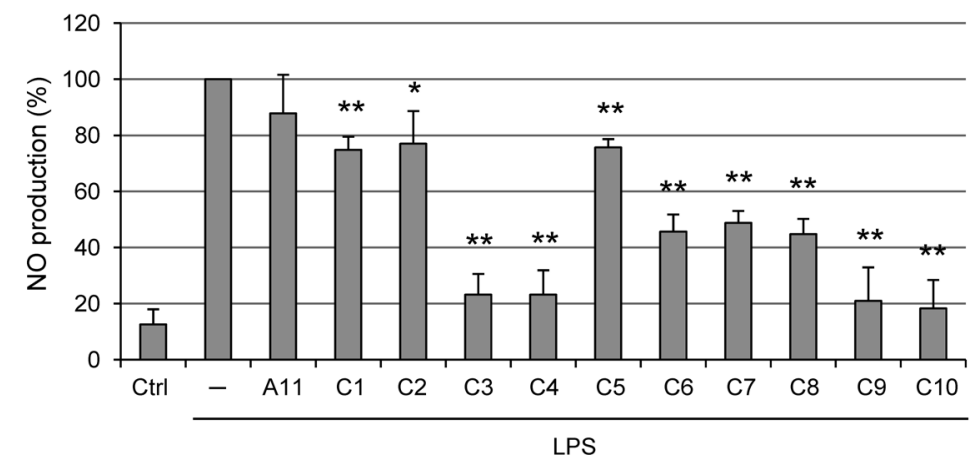

C)

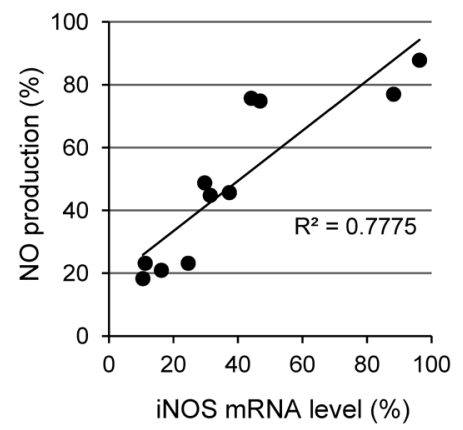

D)

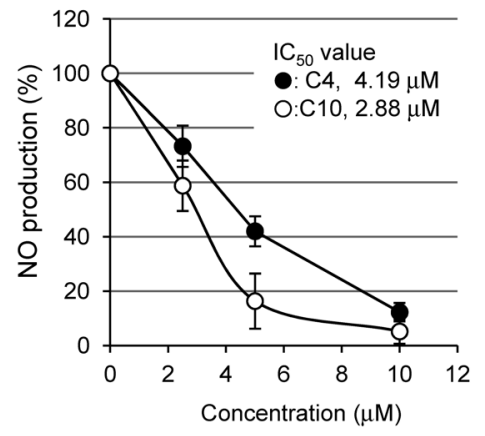

Fig. 2. Effects of Compounds on LPS-Induced iNOS Expression and NO Production

(A) HAPI cells were treated with LPS $(100 \mathrm{ng} / \mathrm{mL})$ for $6 \mathrm{~h}$ in the presence or absence of compounds $(\mathbf{C 1}-\mathbf{C 1 0}$ and A11, $10 \mu \mathrm{M})$. After the treatment, total RNA was extracted, and then RT-PCR was performed. Values (mean \pm S.E.M., $n=3$ ) are expressed as a percentage relative to the mRNA expression level in cells treated with LPS alone. $* p<0.05$ and $* * p<0.01$, respectively ( $v s$. cells treated with LPS alone). (B) HAPI cells were treated with LPS (100 ng/mL) for $24 \mathrm{~h}$ in the presence or absence of compounds $(\mathbf{C 1}-\mathbf{C 1 0}$ and $\mathbf{A 1 1}, 10 \mu \mathrm{M})$. After the treatment, nitrite level in culture medium was measured. Values (mean \pm S.D., $n=3$ ) are expressed as a percentage relative to the nitrite level in cells treated with LPS alone. ${ }^{*} p<0.05$ and $* * p<0.01$, respectively ( $v s$. cells treated with LPS alone). (C) Correlation between inhibitory effects of compounds on iNOS expression and NO production. (D) Dose-dependent study of $\mathbf{C 4}$ and $\mathbf{C 1 0}$ on NO production. HAPI cells were treated with LPS (100 ng/mL) for $24 \mathrm{~h}$ at the indicated concentrations of $\mathbf{C} \mathbf{4}$ or $\mathbf{C 1 0}$. After the treatment, nitrite levels in culture medium were measured. Values (mean \pm S.D., $n=3$ ) are expressed as a percentage relative to the nitrite level in cells treated with LPS alone. 
determined using Bio-Rad protein assay reagent.

Western Blotting Whole-cell lysates $(40 \mu \mathrm{g})$ or nuclear extracts $(10 \mu \mathrm{g})$ were separated by sodium dodecyl sulfatepolyaclylamidegel electrophoresis (SDS-PAGE) on $12 \%(\mathrm{w} / \mathrm{v})$ polyacrylamide gels. After being transferred onto a polyvinylidene difluoride (PVDF) membrane, the blotted membrane was blocked using PBS containing 1\% BSA. The membrane was sequentially incubated with each primary antibody $(1: 3000)$, biotin-conjugated second antibody $(1: 3000)$, and $\mathrm{ABC}$ reagents (Vector Laboratories, Inc., Burlingame, CA, U.S.A.) (1:5000), and then visualized using the Super-signal West Pico Chemiluminescent Substrate (Thermo Fisher Scientific Inc., Waltham, MA, U.S.A.).

Statistical Analysis Data were analyzed using ANOVA followed by post hoc Bonferroni tests or Student's $t$-test. A $p$ value less than 0.05 was considered significant.

\section{RESULTS}

Chemistry We previously demonstrated that 'hidabeni' chalcone glycoside derivatives prevent LPS-induced iNOS expression in HAPI cells. ${ }^{17)}$ To explore compounds with more potent inhibitory effects on LPS-induced iNOS expression, we synthesized ten compounds based on the 'hidabeni' chalcone skeleton (Fig. 1). Chalcones $\mathbf{C 1 - C 1 0}$ were synthesized through the $\mathrm{BF}_{3} \cdot \mathrm{Et}_{2} \mathrm{O}$-mediated Claisen-Schmidt reaction of acetophenones and acetylated benzaldehydes. Acetylated chalcones were deprotected using sodium methoxide in methanol.

Effects of Synthesized Compounds on LPS-Induced iNOS Expression To determine whether the newly synthesized compounds inhibit LPS-induced iNOS mRNA expression, HAPI cells were treated with LPS $(100 \mathrm{ng} / \mathrm{mL})$ for $6 \mathrm{~h}$ in the presence of compounds $(10 \mu \mathrm{M})$. After the treatment, the expression levels of iNOS mRNA were detected using RT-PCR. As shown in Fig. 2A, almost all compounds suppressed LPS-induced iNOS expression, and especially $\mathbf{C 4}$ and C10 had the most potent inhibitory effects. A11, which was previously reported to inhibit iNOS expression at a concentration of $50 \mu \mathrm{M}$, had no effect at a concentration of $10 \mu \mathrm{M}$. We also examined the effects of these compounds on LPSinduced NO production. HAPI cells were treated with LPS $(100 \mathrm{ng} / \mathrm{mL})$ for $24 \mathrm{~h}$ in the presence of compounds $(10 \mu \mathrm{M})$, and then nitrite concentrations were measured in the medium of treated cells. As shown in Fig. 2B, these compounds suppressed LPS-induced NO production. There was a good correlation $\left(R^{2}=0.7775\right)$ between the inhibitory effects of these compounds on LPS-induced iNOS mRNA expression and NO production (Fig. 2C). To determine the $\mathrm{IC}_{50}$ values of $\mathbf{C} 4$ and C10 toward NO production, we carried out dose-dependent experiments. The $\mathrm{IC}_{50}$ values of $\mathbf{C 4}$ and $\mathbf{C 1 0}$ were $4.19 \mu \mathrm{M}$ and

A)

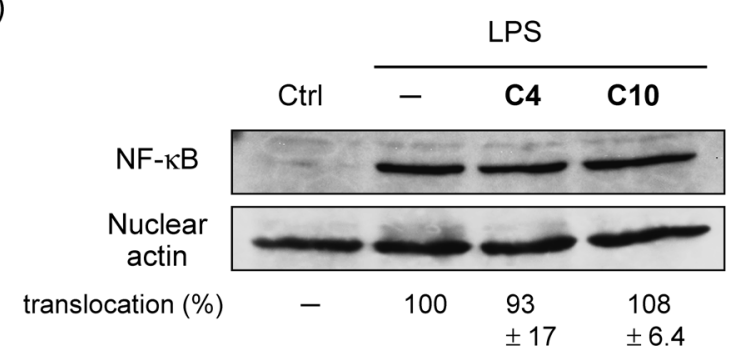

B)
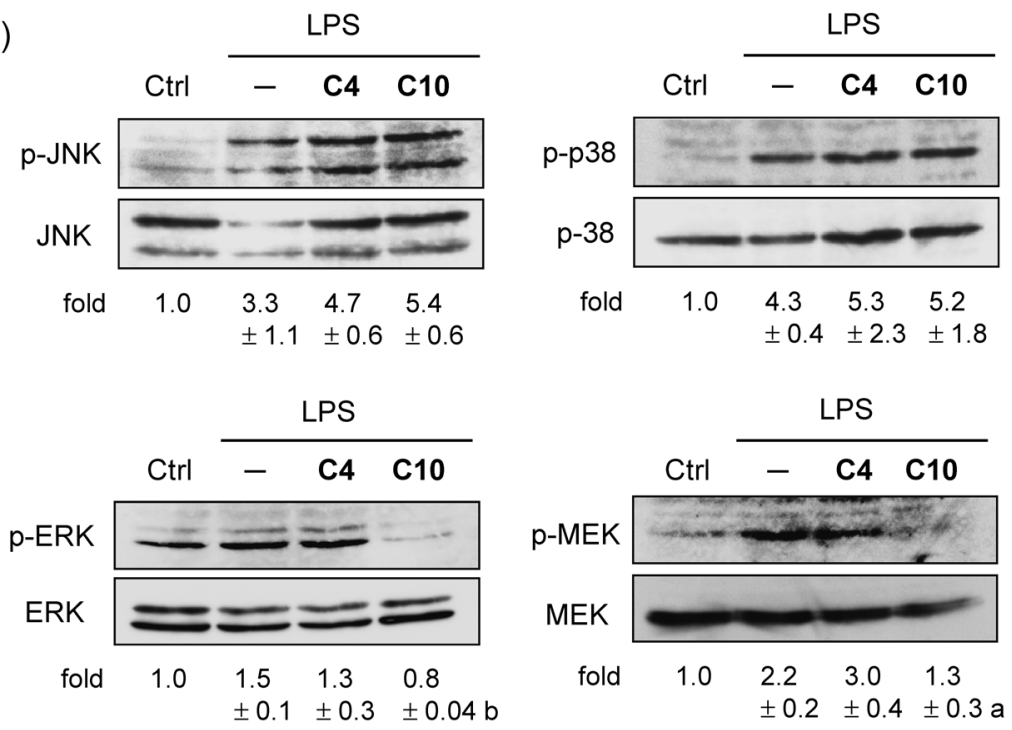

Fig. 3. Effects of $\mathbf{C} 4$ and $\mathbf{C 1 0}$ on NF- $\kappa \mathrm{B}$ and MAPK Pathways

(A) Effects of $\mathbf{C 4}$ and $\mathbf{C 1 0}$ on LPS-induced nuclear translocation of NF- $\kappa$ B. HAPI cells were treated with LPS (100 ng/mL) for $3 \mathrm{~h}$ in the presence or absence of $\mathbf{C 4}$ and C10 $(10 \mu \mathrm{M})$. Nuclear extracts were prepared from the treated cells, and then subjected to Western blot analysis. A representative blot from three independent experiments is shown. Values (mean \pm S.E.M., $n=3$ ) are expressed as a percentage relative to nuclear translocation in cells treated with LPS alone. (B) Effects of C4 and C10 on phosphorylation of MAPKs (JNK, p38, and ERK) and MEK. HAPI cells were treated with LPS (100ng/mL) for $1 \mathrm{~h}$ (JNK, p38, and ERK) or 30 min (MEK) in the presence or absence of C4 and C10 $(10 \mu \mathrm{M})$. Whole-cell lysates were prepared from the treated cells, and then subjected to Western blot analysis. A representative blot from three independent experiments is shown. Values (mean \pm S.E.M., $n=3$ ) are expressed as fold change relative to the ratio of phospho-MAPK or MEK to total MAPK or MEK in untreated cells. ${ }^{\mathrm{a}} p<0.05$ and ${ }^{\mathrm{b}} p<0.01$, respectively ( $v s$. cells treated with LPS alone). 
$2.88 \mu \mathrm{M}$, respectively (Fig. 2D).

Effects of C4 and C10 on LPS-Induced NF- $\kappa$ B Nuclear Translocation and MAPK Activation Since C4 and C10 potently suppressed LPS-induced iNOS expression, we addressed the inhibitory mechanism of these compounds. LPS regulates iNOS expression through NF- $\kappa \mathrm{B}$ and MAPK pathways. Therefore, we investigated whether $\mathbf{C 4}$ and $\mathbf{C 1 0}$ inhibit activation of these pathways caused by LPS. First, to determine the effects of $\mathbf{C 4}$ and $\mathbf{C 1 0}$ on LPS-induced translocation of NF- $\kappa \mathrm{B}$ into the nucleus, HAPI cells were treated with LPS $(100 \mathrm{ng} / \mathrm{mL})$ for $3 \mathrm{~h}$ in the presence of these compounds $(10 \mu \mathrm{M})$ and nuclear extracts prepared from the treated cells were subjected to Western blot analysis. As shown in Fig. 3A, however, C4 and $\mathbf{C 1 0}$ had no effect on NF- $\kappa \mathrm{B}$ nuclear translocation.

Next, to examine the effects of $\mathbf{C 4}$ and $\mathbf{C 1 0}$ on LPSinduced activation of MAPKs, HAPI cells were treated with LPS $(100 \mathrm{ng} / \mathrm{mL})$ for $1 \mathrm{~h}$ in the presence of these compounds $(10 \mu \mathrm{M})$ and then phosphorylation of JNK, p38, and ERK was detected by Western blotting. As shown in Fig. 3B, LPS provoked phosphorylation of JNK and p38. Although the co-treatment with LPS and these compounds tended to increase the phosphorylation levels of JNK compared with the treatment with LPS alone, this alteration was not significant. Likewise, C4 and C10 did not affect the phosphorylation state of p38. LPS only slightly phosphorylated ERK. Interestingly, however, C10, but not C4, suppressed ERK phosphorylation below the basal level (Fig. 3B). Therefore, we examined the effect of $\mathbf{C 1 0}$ on the phosphorylation of MEK, which is an upstream effector of ERK. HAPI cells were treated with LPS $(100 \mathrm{ng} / \mathrm{mL})$ for $30 \mathrm{~min}$ in the presence of $\mathbf{C 4}$ and $\mathbf{C 1 0}(10 \mu \mathrm{M})$, and then phosphorylation of MEK was detected. As expected, C10, but not C4, inhibited LPS-induced MEK phosphorylation (Fig. 3B).

C4 and C10 Suppress LPS-Induced Activation of IFN- $\beta$ Signal and Expression of IRF-1 LPS induces the production of IFN- $\beta$ and stimulates the IFN- $\beta$ autocrine loop, leading to the expression of iNOS. ${ }^{10)}$ Secreted IFN- $\beta$ in LPS-activated macrophages stimulates phosphorylation of STAT1 via the type I interferon receptor. Since LPS-induced iNOS expression has been shown to be suppressed in macrophages prepared from $S T A T 1^{-1-}$ mice, STAT1 is known to be indispensable for this phenomenon. ${ }^{18)}$

Since the IFN- $\beta$ signal plays an important role in LPSinduced iNOS expression, we examined the effects of $\mathbf{C 4}$ and C10 on LPS-induced IFN- $\beta$ mRNA expression. HAPI cells were treated with LPS $(100 \mathrm{ng} / \mathrm{mL})$ for $6 \mathrm{~h}$ in the presence of compounds $(10 \mu \mathrm{M})$ and expression levels of IFN- $\beta$ mRNA were detected using RT-PCR. As shown in Fig. 4A, C4 and C10 significantly suppressed LPS-induced IFN- $\beta$ mRNA expression. Next, to examine whether $\mathbf{C 4}$ and $\mathbf{C 1 0}$ influence LPS-induced STAT1 activation, HAPI cells were treated with LPS $(100 \mathrm{ng} / \mathrm{mL})$ for $3 \mathrm{~h}$ in the presence of these compounds $(10 \mu \mathrm{M})$ and the phosphorylation of STAT1 in the treated cells was detected by Western blotting. As shown in Fig. 4B, C4 and $\mathbf{C 1 0}$ inhibited LPS-induced STAT1 phosphorylation.

In addition to IFN- $\beta$ /STAT1 signaling, IRF-1 has been shown to play a critical role in LPS-induced iNOS expression. ${ }^{19)}$ We also examined the effects of $\mathbf{C 4}$ and $\mathbf{C 1 0}$ on LPSinduced IRF-1 mRNA expression. As shown in Fig. 4C, these compounds significantly suppressed the induction of IRF-1 mRNA caused by LPS.
A)
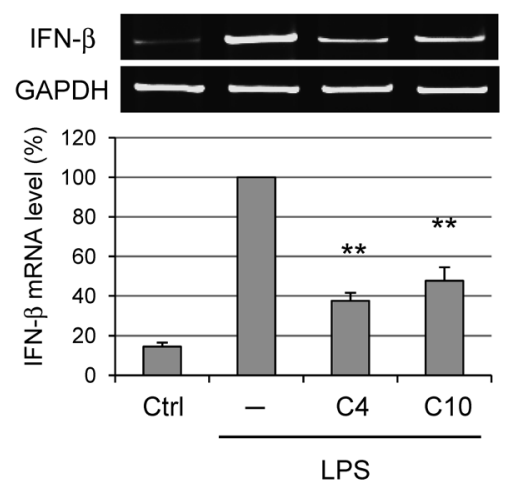

B)
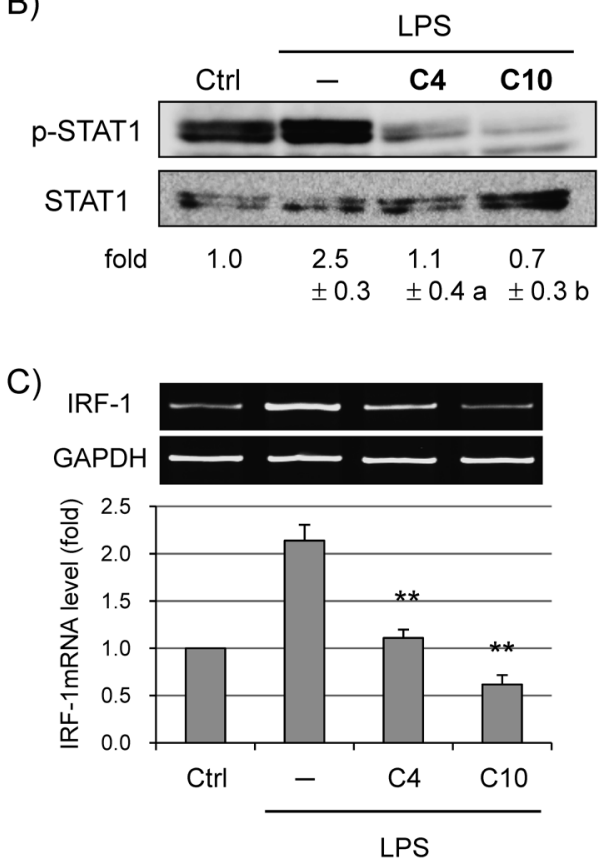

Fig. 4. Involvement of IFN- $\beta$ /STAT1 Signaling and IRF-1 in the Inhibitory Effects of $\mathbf{C 4}$ and $\mathbf{C 1 0}$

(A) Effects of $\mathbf{C 4}$ and $\mathbf{C 1 0}$ on LPS-induced IFN- $\beta$ mRNA expression. HAPI cells were treated with LPS $(100 \mathrm{ng} / \mathrm{mL})$ for $6 \mathrm{~h}$ in the presence or absence of $\mathbf{C} 4$ and $\mathbf{C 1 0}(10 \mu \mathrm{M})$. After the treatment, total RNA was extracted, and then RT-PCR was performed. Values (mean \pm S.E.M., $n=3$ ) are expressed as a percentage relative to the mRNA expression level in cells treated with LPS alone. $* * p<0.01$ ( $v$ s. cells treated with LPS alone). (B) Effects of C4 and C10 on LPS-induced phosphorylation of STAT1. HAPI cells were treated with LPS $(100 \mathrm{ng} / \mathrm{mL})$ for $3 \mathrm{~h}$ in the presence or absence of $\mathbf{C 4}$ and $\mathbf{C 1 0}(10 \mu \mathrm{M})$. After the treatment, whole-cell lysates were prepared from the treated cells, and then subjected to Western blot analysis. A representative blot from four independent experiments is shown. Values (mean \pm S.E.M., $n=4$ ) are expressed as fold change relative to the ratio of phosphoSTAT1 to total STAT1 in untreated cells. a and $\mathrm{b}, p<0.05$ and $p<0.01$, respectively ( $v s$. cells treated with LPS alone). C) Effects of $\mathbf{C 4}$ and $\mathbf{C 1 0}$ on LPS-induced IRF-1 expression. HAPI cells were treated with LPS $(100 \mathrm{ng} / \mathrm{mL})$ for $6 \mathrm{~h}$ in the presence or absence of $\mathbf{C 4}$ and $\mathbf{C 1 0}(10 \mu \mathrm{M})$. After the treatment, total RNA was extracted, and then RT-PCR was performed. Values (mean \pm S.E.M., $n=3$ ) are expressed as a fold change relative to the mRNA expression level in untreated cells. $* * p<0.01$ ( $v s$. cells treated with LPS alone).

Effects of Compounds on LPS-Induced Expression of Proinflammatory Cytokines LPS has been shown to induce various inflammatory cytokines such as TNF- $\alpha$ and IL- $1 \beta .^{18,20)}$ We examined the effects of these compounds on the LPSinduced expression of TNF- $\alpha$ and IL- $1 \beta$ mRNAs. As shown in Fig. 5A, although these compounds suppressed the induction of TNF- $\alpha$ mRNA, they showed little difference in the extent of suppression of TNF- $\alpha$ mRNA expression. Interestingly, however, C10 had a potent inhibitory effect compared with 
A)
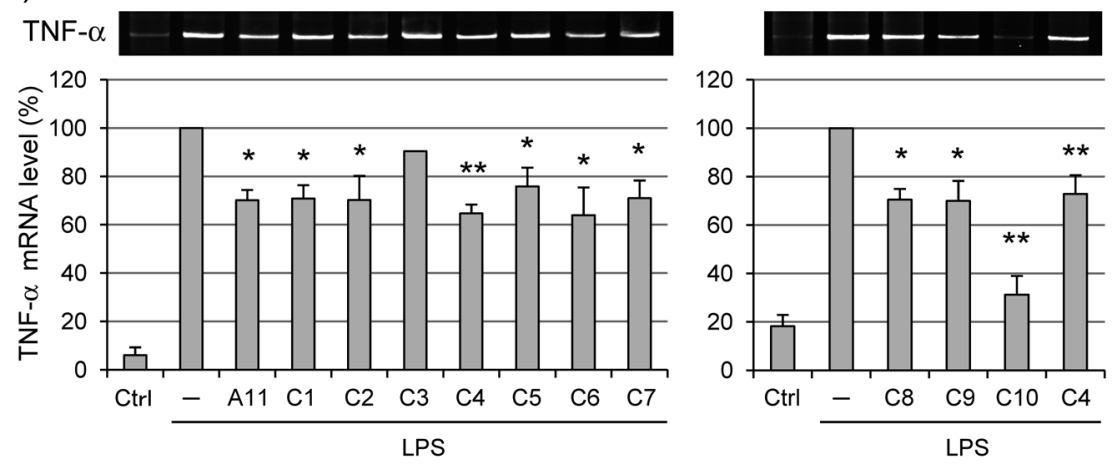

B)
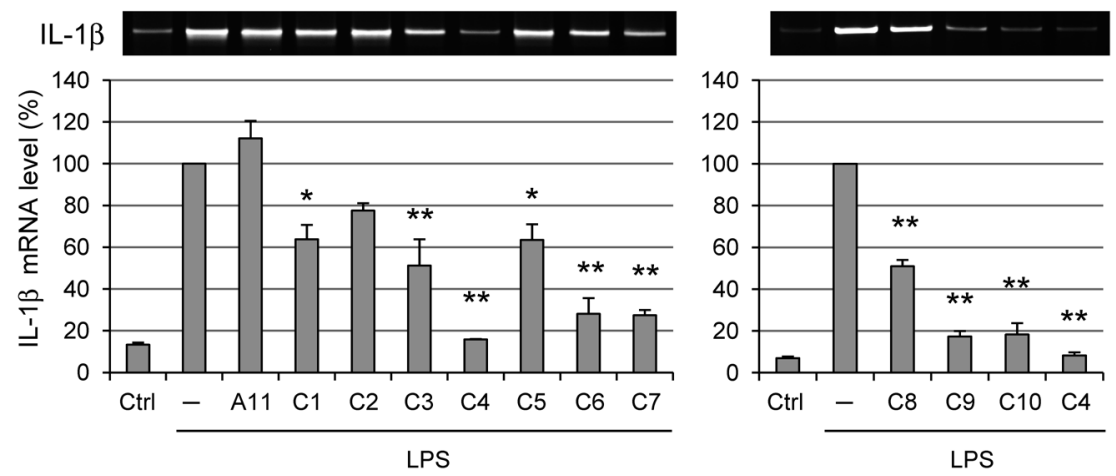

Fig. 5. Effects of Compounds on LPS-Induced TNF- $\alpha$ (A) and IL-1 $\beta$ (B) mRNA Expression

HAPI cells were treated with LPS $(100 \mathrm{ng} / \mathrm{mL})$ for $6 \mathrm{~h}$ in the presence or absence of compounds $(\mathbf{C 1}-\mathbf{C 1 0}, \mathbf{A 1 1}, 10 \mu \mathrm{M})$. After the treatment, total RNA was extracted, and then RT-PCR was performed. Values (mean \pm S.E.M., $n=3-6$ ) are expressed as a percentage relative to the mRNA expression level in cells treated with LPS alone. $* p<0.05$ and $* * p<0.01$, respectively ( $v s$. cells treated with LPS alone).

the other compounds. In contrast, both $\mathbf{C 4}$ and $\mathbf{C 1 0}$ potently inhibited LPS-induced IL-1 $\beta$ mRNA expression (Fig. 5B).

\section{DISCUSSION}

Previously, we reported that 4'-O- $\beta$-D-glucopyranosyl-3',4dimethoxychalcone from the aerial parts of Brassica rapa L. 'hidabeni' and its synthesized derivative 4'-O- $\beta$ D-glucopyranosyl-3'-methoxychalcone (A11) prevent LPSinduced iNOS expression and NO production in HAPI cells. ${ }^{17)}$ In this study, to explore compounds with a more potent inhibitory effect on LPS-induced iNOS expression, we newly synthesized ten chalcones. Almost all chalcone derivatives tested in this study had inhibitory activity toward LPS-induced NO production. The chalcones having monohydroxy and monomethoxy (C7), dimethoxy (C3), monohydroxy and dimethoxy (C6), or trimethoxy $(\mathbf{C 4}, \mathbf{C 8}-\mathbf{C 1 0})$ groups on the $\mathrm{B}$ ring led to augmentation of inhibitory effects compared with the chalcones having a monohydroxy (C5) or monomethoxy (C2) group or no functional group (C1) on the B ring. Additionally, the 3,4,5-trimethoxy-substituted chalcone (C4) more potently inhibited LPS-induced iNOS expression and NO production than 4-monohydroxy and 3,5-dimethoxy-substituted chalcone (C6). Moreover, the chalcone with no functional group on the A ring (C8) was less effective in terms of NO inhibition than those with 4'-monohydroxy (C9) and 3'-monomethoxy (C10) groups. These results indicate that the substitutions with a methoxy group at the $3^{\prime}$ - and/or a hydroxy group at the $4^{\prime}$-position on the A ring and methoxy, but not hydroxy, groups at 3,4-positions or 3,4,5-positions on the B ring are required to acquire potent inhibitory effects by chalcones on LPS-induced NO production.

It has been reported that chalcones prevent LPS-induced proinflammatory cytokines and iNOS expression by the inhibition of NF- $\kappa$ B, JNK, and p38 pathways. $^{13,21-24)}$ We demonstrated here that $\mathbf{C 4}$ and $\mathbf{C 1 0}$ potently suppressed iNOS induction and NO production caused by LPS, but did not affect $\mathrm{NF}-\kappa \mathrm{B}, \mathrm{JNK}$, and p38 pathways. Interestingly, C10, but not C4, potently inhibited the MEK/ERK pathway. However, since both $\mathbf{C 4}$ and $\mathbf{C 1 0}$ inhibited NO production to a similar extent, the inhibition of the MEK/ERK pathway might slightly contribute to the inhibitory effect of C10 on LPS-induced iNOS expression. The structure of $\mathbf{C 1 0}$ is identical to that of C4, except for the substitution of one hydroxy group at the $4^{\prime}$-position on the A ring. Thus, these results indicate that the difference in substitution at the position on the A ring confers specificity in the MEK-ERK pathway. We found that the suppressive effect of $\mathbf{C 1 0}$ on LPS-induced TNF- $\alpha$ mRNA expression was stronger than that of C4. Since LPS-induced TNF- $\alpha$ expression is reported to be involved in ERK, ${ }^{25,26)}$ the inhibitory effect of $\mathbf{C 1 0}$ on the expression of TNF- $\alpha$ may be attributable to inhibition of the MEK/ERK pathway by C10. Compounds other than $\mathbf{C 1 0}$ partially prevented induction of TNF- $\alpha$ by LPS. At present, we do not know the details of how these compounds suppress TNF- $\alpha$ induction. However, we have previously found that several inhibitors, such as LY294002 (phosphatidylinositol 3-kinase), diphenyleneiodonium (NADPH oxidase), and PP2 (Src family kinase), prevent LPS-induced TNF- $\alpha$ mRNA expression in this cell line (unpublished data). Therefore, it is likely that inhibitory 
action of these compounds on other pathway(s) contributes to prevention of TNF- $\alpha$ induction.

IFN- $\beta /$ STAT1 signaling plays a key role in LPS-induced iNOS expression. ${ }^{10)}$ We found that $\mathbf{C 4}$ and $\mathbf{C 1 0}$ suppressed LPS-induced IFN- $\beta$ expression in HAPI cells (Fig. 4A). In addition, these compounds inhibited STAT1 phosphorylation caused by LPS (Fig. 4B). Therefore, it is likely that the suppression of IFN- $\beta$ production by these compounds is due to the prevention of STAT1 activation. Previously, however, we reported that the synthesized chalcone glycoside A11 hardly affects IFN- $\beta$ production but decreases STAT1 activation by LPS. ${ }^{17)}$ In contrast, it has been shown that other tyrosine protein kinases such as EGF receptor and c-Src mediate phosphorylation of STAT1. ${ }^{27,28)}$ Thus, we cannot rule out the possibility that $\mathbf{C 4}$ and $\mathbf{C 1 0}$ inhibit STAT1 phosphorylation independently of type I IFN receptor activation by IFN- $\beta$.

Likewise, IRF-1 has been shown to be an essential transcription factor for LPS-induced iNOS expression because LPS fails to provoke iNOS expression in IRF-1-deficient macrophages. ${ }^{19)} \mathbf{C 4}$ and $\mathbf{C 1 0}$ suppressed LPS-induced IRF-1 mRNA expression in HAPI cells (Fig. 4C). Therefore, the inhibitory effect of $\mathbf{C 4}$ and $\mathbf{C 1 0}$ on iNOS induction is likely to be attributable, at least in part, to suppression of IRF-1 expression by these compounds. In addition, IRF-1 is reported to bind to the promoter region of IFN- $\beta$ and up-regulates its expression. $^{29)}$ Thus, it is possible that suppression of LPSinduced IRF-1 expression by $\mathbf{C 4}$ and $\mathbf{C 1 0}$ inhibits IFN- $\beta$ production and leads to prevention of induction of the IFN- $\beta$ / STAT1 pathway. Besides IFN- $\beta$ and iNOS, IRF-1 has been shown to mediate the expression of various inflammatory factors. ${ }^{30)}$ Therefore, inhibition of IRF-1 induction caused by C4 and C10 might decrease LPS-induced IL- $1 \beta$ expression in HAPI cells.

The blood-brain barrier (BBB) permeability of compounds is critical to develop drugs for the CNS diseases. At present, whether compounds tested in this study penetrate the BBB is unknown. However, flavonoids have been shown to be able to traverse the BBB in in vitro and in situ models. ${ }^{31)}$ Additionally, in vivo studies using middle cerebral artery occlusion model have demonstrated that flavonoids and chalcones protect against brain injury caused by cerebral ischemia. ${ }^{32,33)}$ Therefore, the 'hidabeni' chalcone derivatives $\mathbf{C 4}$ and $\mathbf{C 1 0}$ could penetrate the BBB.

In conclusion, we found that 3',3,4,5-tetramethoxy-4'hydroxychalcone (C4) and 3',3,4,5-tetramethoxychalcone (C10) have potent inhibitory activity on LPS-induced NO production. Although several chalcone derivatives have been reported to inhibit LPS-induced activation of NF- $\kappa$ B and JNK pathways, C4 and C10 did not affect these pathways. Our results suggest that the mechanism by which the compounds suppress LPS-induced iNOS expression differs from that of previously reported chalcones. Therefore, we think that $\mathbf{C 4}$ and $\mathbf{C 1 0}$ may be good candidates to develop novel mechanism-based therapeutic drugs for neurodegenerative diseases associated with microglia.

Acknowledgment This work was supported by a Grantin-Aid for Scientific Research (C) from the Japan Society for the Promotion of Science (No. 23590644).

\section{REFERENCES}

1) Cameron B, Landreth GE. Inflammation, microglia, and Alzheimer's disease. Neurobiol. Dis., 37, 503-509 (2010).

2) Shichita T, Hasegawa E, Kimura A, Morita R, Sakaguchi R, Takada I, Sekiya T, Ooboshi H, Kitazono T, Yanagawa T, Ishii T, Takahashi H, Mori S, Nishibori M, Kuroda K, Akira S, Miyake K, Yoshimura A. Peroxiredoxin family proteins are key initiators of post-ischemic inflammation in the brain. Nat. Med., 18, 911-917 (2012).

3) Weinstein JR, Koerner IP, Moller T. Microglia in ischemic brain injury. Future Neurol., 5, 227-246 (2010).

4) Bal-Price A, Brown GC. Inflammatory neurodegeneration mediated by nitric oxide from activated glia-inhibiting neuronal respiration, causing glutamate release and excitotoxicity. J. Neurosci., 21, 6480-6491 (2001).

5) Knoch ME, Hartnett KA, Hara H, Kandler K, Aizenman E. Microglia induce neurotoxicity via intraneuronal $\mathrm{Zn}^{2+}$ release and a $\mathrm{K}^{+}$ current surge. Glia, 56, 89-96 (2008).

6) Keynes RG, Garthwaite J. Nitric oxide and its role in ischaemic brain injury. Curr. Mol. Med., 4, 179-191 (2004).

7) Buchanan MM, Hutchinson M, Watkins LR, Yin H. Toll-like receptor 4 in CNS pathologies. J. Neurochem., 114, 13-27 (2010).

8) Chan ED, Riches DW. IFN- $\gamma+$ LPS induction of iNOS is modulated by ERK, JNK/SAPK, and p38(mapk) in a mouse macrophage cell line. Am. J. Physiol. Cell Physiol., 280, C441-C450 (2001).

9) Kleinert H, Schwarz PM, Forstermann U. Regulation of the expression of inducible nitric oxide synthase. Biol. Chem., 384, 1343-1364 (2003).

10) Jacobs AT, Ignarro LJ. Lipopolysaccharide-induced expression of interferon- $\beta$ mediates the timing of inducible nitric-oxide synthase induction in RAW264.7 macrophages. J. Biol. Chem., 276, 4795047957 (2001).

11) Hyakkoku K, Hamanaka J, Tsuruma K, Shimazawa M, Tanaka H, Uematsu S, Akira S, Inagaki N, Nagai H, Hara H. Toll-like receptor 4 (TLR4), but not TLR3 or TLR9, knock-out mice have neuroprotective effects against focal cerebral ischemia. Neuroscience, 171, 258-267 (2010)

12) Yang QW, Lu FL, Zhou Y, Wang L, Zhong Q, Lin S, Xiang J, Li JC, Fang CQ, Wang JZ. HMBG1 mediates ischemia-reperfusion injury by TRIF-adaptor independent Toll-like receptor 4 signaling. J. Cereb. Blood Flow Metab., 31, 593-605 (2011).

13) Cheng Z, Lin C, Hwang T, Teng C. Broussochalcone A, a potent antioxidant and effective suppressor of inducible nitric oxide synthase in lipopolysaccharide-activated macrophages. Biochem. Pharmacol., 61, 939-946 (2001).

14) Lee JH, Jung HS, Giang PM, Jin X, Lee S, Son PT, Lee D, Hong YS, Lee K, Lee JJ. Blockade of nuclear factor-kappaB signaling pathway and anti-inflammatory activity of cardamomin, a chalcone analog from Alpinia conchigera. J. Pharmacol. Exp. Ther., 316, 271-278 (2006)

15) Yamamoto T, Yoshimura M, Yamaguchi F, Kouchi T, Tsuji R, Saito M, Obata A, Kikuchi M. Anti-allergic activity of naringenin chalcone from a tomato skin extract. Biosci. Biotechnol. Biochem., 68, 1706-1711 (2004)

16) Ninomiya M, Efdi M, Inuzuka T, Koketsu M. Chalcone glycosides from aerial parts of Brassica rapa L. 'hidabeni,' turnip. Phytochem. Lett., 3, 96-99 (2010).

17) Hara H, Nakamura Y, Ninomiya M, Mochizuki R, Kamiya T, Aizenman E, Koketsu M, Adachi T. Inhibitory effects of chalcone glycosides isolated from Brassica rapa L. 'hidabeni' and their synthetic derivatives on LPS-induced NO production in microglia. Bioorg. Med. Chem., 19, 5559-5568 (2011).

18) Ohmori Y, Hamilton TA. Requirement for STAT1 in LPS-induced gene expression in macrophages. J. Leukoc. Biol., 69, 598-604 (2001).

19) Shiraishi A, Dudler J, Lotz M. The role of IFN regulatory factor-1 
in synovitis and nitric oxide production. J. Immunol., 159, 35493554 (1997).

20) Joshi VD, Kalvakolanu DV, Chen W, Zhang L, Kang TJ, Thomas KE, Vogel SN, Cross AS. A role for Stat1 in the regulation of lipopolysaccharide-induced interleukin- $1 \beta$ expression. J. Interferon Cytokine Res., 26, 739-747 (2006).

21) Ahmad S, Israf DA, Lajis NH, Shaari K, Mohamed H, Wahab AA, Ariffin KT, Hoo WY, Aziz NA, Kadir AA, Sulaiman MR, Somchit MN. Cardamonin, inhibits pro-inflammatory mediators in activated RAW264.7 cells and whole blood. Eur. J. Pharmacol., 538, 188-194 (2006).

22) Ban HS, Suzuki K, Lim SS, Jung SH, Lee S, Ji J, Lee HS, Lee YS, Shin KH, Ohuchi K. Inhibition of lipopolysaccharide-induced expression of inducible nitric oxide synthase and tumor necrosis factor-a by 2 '-hydroxychalcone derivatives in RAW264.7 cells. Biochem. Pharmacol., 67, 1549-1557 (2004).

23) Cho YC, Kim HJ, Kim YJ, Lee KY, Choi HJ, Lee IS, Kang BY. Differential anti-inflammatory pathway by xanthohumol in IFN- $\gamma$ and LPS-activated macrophages. Int. Immunopharmacol., 8, 567573 (2008)

24) Kim JY, Park SJ, Yun KJ, Cho YW, Park HJ, Lee KT. Isoliquiritigenin isolated from the roots of Glycyrrhiza uralensis inhibits LPSinduced iNOS and COX-2 expression via the attenuation of NF-kB in RAW264.7 macrophages. Eur. J. Pharmacol., 584, 175-184 (2008).

25) Carter AB, Monick MM, Hunninghake GW. Both Erk and p38 kinases are necessary for cytokine gene transcription. Am. J. Respir. Cell Mol. Biol., 20, 751-758 (1999).
26) Shi L, Kishore R, McMullen MR, Nagy LE. Lipopolysaccharide stimulation of ERK1/2 increases TNF- $\alpha$ production via Egr-1. Am. J. Physiol. Cell Physiol., 282, C1205-C1211 (2002).

27) Andersen P, Pedersen MW, Woetmann A, Villingshoj M, Stockhausen MT, Odum N, Poulsen HS. EGFR induces expression of IRF-1 via STAT1 and STAT3 activation leading to growth arrest of human cancer cells. Int. J. Cancer, 122, 342-349 (2008).

28) Chang YJ, Holtzman MJ, Chen CC. Differential role of Janus family kinases (JAKs) in interferon- $\gamma$-induced lung epithelial ICAM-1 expression: involving protein interactions between JAKs, phospholipase C $\gamma$, c-Src, and STAT1. Mol. Pharmacol., 65, 589-598 (2004).

29) Kirchhoff S, Wilhelm D, Angel P, Hauser H. NFkB activation is required for interferon regulatory factor-1-mediated interferon beta induction. Eur. J. Biochem., 261, 546-554 (1999).

30) Marecki S, Riendeau CJ, Liang MD, Fenton MJ. PU.1 and multiple IFN regulatory factor proteins synergize to mediate transcriptional activation of the human IL-1 $\beta$ gene. J. Immunol., 166, 6829-6838 (2001).

31) Youdim KA, Qaiser MZ, Begley DJ, Rice-Evans CA, Abbott NJ. Flavonoid permeability across an in situ model of the blood-brain barrier. Free Radic. Biol. Med., 36, 592-604 (2004).

32) Shah ZA, Li RC, Ahmad AS, Kensler TW, Yamamoto M, Biswal S, Dore S. The flavanol (-)-epicatechin prevents stroke damage through the Nrf2/HO1 pathway. J. Cereb. Blood Flow Metab., 30, 1951-1961 (2010).

33) Zhan C, Yang J. Protective effects of isoliquiritigenin in transient middle cerebral artery occlusion-induced focal cerebral ischemia in rats. Pharmacol. Res., 53, 303-309 (2006). 